\title{
UMEDECIMENTO DO SUBSTRATO NA EMERGÊNCIA E VIGOR DE PLÂNTULAS DE PUPUNHEIRA ${ }^{1}$
}

\author{
CIBELE CHALITAMARTINS ${ }^{2}$, MARILENELEÃO ALVES BOVI $^{3}$, SANDRA HEIDEN SPIERING $^{4}$
}

RESUMO - A germinação rápida e uniforme das sementes, seguida por pronta emergência das plântulas são características altamente desejáveis na formação de mudas. O objetivo deste trabalho foi verificar o efeito de diferentes níveis de umedecimento do substrato vermiculita sobre a porcentagem de emergência e o vigor de plântulas de pupunheira. O umedecimento da vermiculita com água nas quantidades de 60 a $90 \mathrm{ml} / 100 \mathrm{~g}$ de substrato (de 0,6 a 0,9 x o peso deste em água ou 77,6 a 86,7\% da capacidade de retenção do substrato em água, respectivamente) resultaram na maior porcentagem de emergência das plântulas. $\mathrm{O}$ umedecimento com $90 \mathrm{ml}$ água/ $100 \mathrm{~g}$ de vermiculita resultou em maior velocidade de emergência e vigor de plântulas (comprimento, diâmetro e massa).

Termos para indexação: germinação, mudas, Bactris gasipaes, vermiculita.

\section{SUBSTRATE MOISTURE LEVEL EFFECT ON SEEDLING EMERGENCY AND VIGOR OF PEACH PALM}

\begin{abstract}
The rapid and uniform germination of seeds, followed by prompt emergency are highly desirable characteristics for seedlings formation. This research aimed to determine the effect of different level of vermiculite substrate wetting on the emergency percentage and vigor of peach palm seedlings. The wetting of vermiculite with water in quantities from 60 to $90 \mathrm{ml} / 100 \mathrm{~g}$ of substrate (from 0.6 to $0.9 \mathrm{x}$ the weight of water or 77.6 to $86.7 \%$ of the retention capacity of the substrate in water, respectively) had shown higher emergence percentage of seedlings. The wetting with $90 \mathrm{ml}$ water / $100 \mathrm{~g}$ of vermiculite resulted in the higher speed of emergency and vigor of seedlings (length, diameter and mass).
\end{abstract}

Index Terms: germination, seedlings, Bactris gasipaes, vermiculite.

\section{INTRODUÇÃO}

A expansão da área de cultivo de pupunheira, ocorrida a partir da década de 90 , fez crescer a procura por sementes e mudas dessa palmeira, utilizada para a produção de frutos e de palmito.

Uma germinação rápida e uniforme das sementes, seguida por pronta emergência das plântulas são características altamente desejáveis na formação de mudas, pois quanto mais tempo a plântula permanecer nos estádios iniciais de desenvolvimento mais vulnerável estará às condições adversas do meio. Assim, o estabelecimento da plântula de pupunheira vai depender da qualidade fisiológica das sementes e de fatores ambientais, tais como luz, temperatura, aeração e disponibilidade hídrica do substrato.

A qualidade fisiológica de sementes de palmeiras vem sendo avaliada por testes de germinação e vigor (Iossi et al., 2003; Elias et al., 2006; Ferreira \& Gentil, 2006 ). Resultados discrepantes são relatados em trabalhos de pesquisa e, algumas vezes, atribuídos à variabilidade genética do material. No entanto, resultados divergentes podem ser obtidos em consequência da maior ou menor disponibilidade hídrica dos substratos utilizados (Ledo et al., 2002; Iossi et al., 2003). A vermiculita é um substrato comumente utilizado para a produção de mudas devido a vantagens como: fácil obtenção, baixa densidade, uniformidade na composição química e granulométrica, porosidade e capacidade de retenção de água.

As sementes de pupunheira apresentam sensibilidade à desidratação, deixando de germinar em teores de água inferiores a 18\%, sendo consideradas recalcitrantes (Ferreira \& Santos, 1992). Contrariamente às ortodoxas, as sementes recalcitrantes continuam com elevado teor de água até o final do desenvolvimento e maturação (Fonseca \& Freire, 2003). Contudo, após a semeadura, não havendo disponibilidade hídrica suficiente no substrato, o processo de germinação pode ser

${ }^{1}$ (Trabalho 129-08). Recebido em: 27-05-2008. Aceito para publicação em: 04-11-2008.

${ }^{2}$ Dr. Eng. Agrônomo, Depto. Produção Vegetal, FCA/UNESP, Botucatu-SP.

${ }^{3}$ Dr. Eng. Agrônomo, Centro de Horticultura, Seção de Plantas Tropicais IAC/SAA, Campinas-SP "in memorian".

${ }^{4}$ Bióloga, Centro de Horticultura, Seção de Plantas Tropicais, IAC/SAA, Campinas-SP. 
seriamente prejudicado, podendo ocorrer a morte do embrião (Marcos Filho, 2005).

De forma oposta, o excesso de água no substrato pode prejudicar o processo germinativo devido à menor aeração (Marcos Filho, 2005). Durante a germinação de sementes de pupunheira, o excesso de água pode causar o apodrecimento das sementes e doenças nas plântulas (Nishikawa et al., 1998).

Embora não tenham sido encontrados trabalhos sobre o umedecimento do substrato na germinação de sementes recalcitrantes ou de sementes de espécies frutíferas, esse assunto foi estudado para sementes ortodoxas de várias espécies (Phaneendranat, 1980; Tao, 1981; Toledo \& Pedreira, 1984; Varela et al., 2005; Ramos et al., 2006).

Devido à importância da utilização da quantidade certa de água para a germinação, as Regras para Análise de Sementes (Brasil, 1992) passaram a normatizar o umedecimento do substrato, recomendando para o teste de germinação em papel a adição de um volume de água equivalente a 2,0 até 2,5 vezes (gramínea) ou 2,5 a 3,0 vezes (leguminosa) o peso do substrato. Em areia, é recomendado o umedecimento com até $50 \%$ e $60 \%$ da capacidade de retenção do substrato em água, para sementes de cereais e de leguminosas, respectivamente. Para vermiculita, não há recomendações, e a quase totalidade dos trabalhos de pesquisa que estudam diferentes substratos na germinação de sementes de palmeiras, não fazem referências à quantidade de água adicionada aos diferentes substratos, o que pode resultar em conclusões equivocadas sobre o assunto.

O objetivo do presente trabalho foi verificar o efeito de diferentes níveis de umedecimento do substrato sobre a porcentagem de emergência e o vigor de plântulas de pupunheira.

\section{MATERIAL E MÉTODOS}

O presente experimento foi realizado no laboratório do Centro de Horticultura - Unidade de Plantas Tropicais, do Instituto Agronômico, localizado em Campinas-SP. Foram utilizados seis lotes de sementes comerciais de pupunheira sem espinhos (Bactris gasipaes Kunth), provenientes de Yurimaguas, Peru, com teor de água não inferior a $44,5 \%$ para garantia da qualidade fisiológica, conforme preconiza Ferreira \& Santos (1992). O teor de água das sementes foi determinado pelo método da estufa com duas repetições de 7 sementes por lote, a $105 \pm 3^{\circ} \mathrm{C} / 24$ horas (Brasil, 1992).

Para maior padronização do material, foram selecionadas sementes com comprimento entre $25 \mathrm{e}$
$29 \mathrm{~mm}$ e sem sinais visíveis do início do processo germinativo. A amostragem foi manual, e cada lote foi homogeneizado duas vezes e reduzido pelo método das divisões sucessivas, com o auxílio de uma régua para a obtenção das amostras médias (Brasil, 1992), de aproximadamente $200 \mathrm{~g}$ por lote. As amostras médias foram misturadas, homogeneizadas duas vezes e reduzidas pelo método das divisões sucessivas (Brasil, 1992) para a obtenção de uma única amostra de trabalho de 100 g.

Os diferentes teores de umidade do substrato foram obtidos através da adição de água nas quantidades equivalentes a $0 ; 30 ; 60 ; 90 ; 120 \mathrm{e}$ $150 \mathrm{ml}$ por $100 \mathrm{~g}$ de vermiculita, o que corresponde a 0,$0 ; 0,3 ; 0,6 ; 0,9 ; 1,2$ e $1,5 \mathrm{vez}$ o peso do substrato em água. O cálculo do umedecimento e da capacidade máxima de retenção de água do substrato foi avaliado adaptando-se a metodologia prescrita para areia nas Regras para Análise de Sementes (Brasil, 1992), colocando-se 100g de vermiculita em um filtro de papel e adicionando-se uma quantidade de água previamente determinada. Decorridos 15 minutos, foi determinado por diferença o volume de água retido pelo substrato, que representa $100 \%$ da capacidade de retenção da vermiculita e, por meio de regra de três, calculou-se a quantidade de água a ser adicionada em cada tratamento (Tabela 1).

O teor de umidade inicial e final do substrato foi determinado para cada tratamento pelo método de estufa ( $105 \pm 3^{\circ} \mathrm{C} / 24$ horas), comumente utilizado para avaliar o teor de água de sementes (Brasil, 1992). Antes de adicionar as doses de água ao experimento, a vermiculita foi mantida a $120^{\circ} \mathrm{C}$, por 12 horas, para a esterilização e secagem, que possibilitaria a obtenção de um substrato sem água e a confiabilidade dos tratamentos testados.

Para avaliar o efeito do teor de umidade do substrato sobre a qualidade das sementes e plântulas, foram utilizados os seguintes testes: teste de emergência de plântulas - conduzido com quatro repetições de 20 sementes, semeadas na posição paralela a sua maior dimensão e com o poro germinativo para cima, entre vermiculita de granulação média (diâmetro de 2,4 a 2,7 mm), esterilizada $\left(120^{\circ} \mathrm{C} / 12\right.$ horas). Para o teste, colocaramse $250 \mathrm{ml}$ e $100 \mathrm{ml}$ do substrato umedecido embaixo e sobre a semente, respectivamente, dentro de potes plásticos transparentes, tampados $(12 \mathrm{~cm}$ diâmetro e $14 \mathrm{~cm}$ altura), sobre a bancada do laboratório, em condições de luz indireta e temperatura de $19,5 \pm 3,5^{\circ} \mathrm{C}$. Procedeu-se ao rodízio periódico das posições dos potes de forma a homogeneizar as condições ambientais do ensaio. A contagem das 
plântulas foi realizada semanalmente, até o 119o dia após a semeadura, quando foi calculada a porcentagem de germinação, baseada na contagem das plântulas normais (Brasil, 1992).

Índice de Velocidade de Emergência (I.V.E.) e duração média do processo germinativo determinados, respectivamente, por meio de critérios estabelecidos por Maguire (1962) e Bianchetti \& Amaral (1978), contabilizando-se semanalmente as plântulas normais do teste de emergência de plântulas. Comprimento $(\mathrm{cm})$ da parte aérea, do sistema radicular e diâmetro da plântula mensurando-se com o auxílio de uma régua graduada os comprimentos e, com paquímetro, o diâmetro do coleto a $0,5 \mathrm{~cm}$ de altura, de todas as plântulas normais no final do teste de emergência (Nakagawa, 1994). Massa seca - ao final do teste de emergência, as plântulas foram retiradas, secadas em estufa a $80^{\circ} \mathrm{C} / 24$ horas e pesadas em balança de precisão. Os resultados foram calculados em mg de matéria seca por plântula e foi considerada, para o cálculo da média de cada repetição, a população de plântulas normais (Nakagawa, 1994).

O delineamento experimental foi 0 completamente casualizado, com quatro repetições de 20 sementes por tratamento e, devido à natureza quantitativa dos tratamentos (umedecimento com 0; 30; 60; 90; 120 e $150 \mathrm{ml}$ de água por $100 \mathrm{~g} \mathrm{de}$ vermiculita que corresponde a 0,$0 ; 0,3 ; 0,6 ; 0,9 ; 1,2 \mathrm{e}$ 1,5 vez o peso do substrato em água), foi feita análise de regressão e ajuste de curvas, estimando-se os pontos que proporcionaram otimização das variáveis mensuradas.

\section{RESULTADOS E DISCUSSÃO}

O teor médio inicial de água das sementes por ocasião da semeadura foi de $47,5 \%$, valor suficiente para a manutenção da capacidade germinativa das sementes de pupunheira, que são recalcitrantes (Ferreira \& Santos, 1992). Não houve reumedecimento dos substratos durante o decorrer do experimento, mesmo assim houve pouca variação entre os teores de umidade iniciais e finais do substrato (Figura 1). Assim, na maioria dos tratamentos, verificou-se que os potes plásticos tampados foram eficientes na manutenção da umidade do sistema durante todo o período de condução do teste de emergência de plântulas e que a abertura semanal destes para a contagem de plântulas pode ter causado a perda de água verificada.

Nas condições em estudo, o processo de germinação tornou-se visível, pela emergência das plântulas, a partir do $35^{\circ}$ dia após o início do experimento e, aos 56 dias após a semeadura, aproximadamente $50 \%$ do total das plântulas haviam emergido dos substratos com adição de água (Figura 2).

Somente o substrato sem adição de água impossibilitou a germinação e a emergência das plântulas (Figura 2), provavelmente devido à morte do embrião após a semeadura, por não haver disponibilidade hídrica suficiente no substrato (Marcos Filho, 2005).

O umedecimento do substrato com quantidades entre 60 a $90 \mathrm{ml}$ de água em $100 \mathrm{~g} \mathrm{de}$ substrato proporcionou máxima porcentagem de emergência das plântulas verificada nas contagens realizadas a partir dos 56 dias após a semeadura (Figura 2); embora, em comparação ao tratamento sem umedecimento, as demais condições de umedecimento do substrato $(30 ; 120$ e $150 \mathrm{ml} / 100 \mathrm{~g})$ também tenham elevado a emergência a valores estatisticamente significativos. Na Figura 3, verificouse a duração média do processo germinativo de 70 a 77 dias, para os dados originais, e de 65 a 80 dias para a curva ajustada, para as condições de umedecimento entre 30 e $150 \mathrm{ml}$ de água em $100 \mathrm{~g}$ de substrato.

Portanto, para sementes de pupunheira, o teor de água relativamente alto da semente $(47,5 \%)$ não seria suficiente para desencadear as atividades metabólicas do processo germinativo sem a necessidade de um suprimento de água adicional do substrato, embora este suprimento seja proporcionalmente menor do que seria o exigido no caso das sementes ortodoxas (Phaneendranat, 1980; Tao, 1981; Toledo \& Pedreira, 1984; Brasil, 1992; Varela et al., 2005; Ramos et al., 2006), que apresentam teor de água entre 8 e $13 \%$ por ocasião da semeadura.

A velocidade da emergência e a qualidade da plântula resultante (comprimento, diâmetro e massa) indicaram que a disponibilidade hídrica do substrato afetou o crescimento da plântula (Figuras 4; 5; 6 e 7). O índice de velocidade de emergência de plântulas, o comprimento do sistema radicular e o diâmetro do coleto (Figuras 4; 5 e 6) apresentaram valores máximos em condições de umedecimento entre 60 e $90 \mathrm{ml}$ de água em $100 \mathrm{~g}$ de substrato, enquanto para o comprimento de parte aérea de plântulas isso ocorreu em condições de umedecimento com quantidades iguais ou superiores a $90 \mathrm{ml}$ (Figura 5). Para a massa seca de plântulas, o ponto de máxima foi obtido em substrato umedecido com 90ml (Figura 7).

Portanto, de forma geral, o umedecimento com $90 \mathrm{ml}$ de água em $100 \mathrm{~g}$ de substrato $(0,9 \mathrm{x}$ o peso da vermiculita em água ou $86,7 \%$ da capacidade de retenção da vermiculita em água) foi a condição que 
possibilitou a obtenção dos maiores valores em todos os parâmetros de crescimento de plântulas avaliados, e essas características devem influenciar na qualidade final da muda de pupunheira.

TABELA 1 - Quantidade de água adicionada ao substrato $\left(\mathrm{H}_{2} \mathrm{O}\right)$, referência de umedecimento usando-se como base um valor para a multiplicação do peso do substrato em água e correspondentes teores de umidade do substrato obtidos em relação ao peso seco do substrato (PS) e em relação à capacidade máxima de retenção de água do substrato $(\mathrm{R})$.

\begin{tabular}{cccc}
\hline $\mathrm{H}_{2} \mathrm{O}$ & Vezes o peso do & \multicolumn{2}{c}{ Teor de umidade do substrato (\%) } \\
\cline { 3 - 4 }$(\mathrm{ml} / 100 \mathrm{~g})$ & substrato em água & PS & $\mathrm{R}$ \\
\hline 0 & 0,0 & 5,57 & 7,10 \\
30 & 0,3 & 44,90 & 57,24 \\
60 & 0,6 & 60,90 & 77,64 \\
90 & 0,9 & 67,99 & 86,69 \\
120 & 1,2 & 73,81 & 94,10 \\
150 & 1,5 & 76,32 & 97,30 \\
\hline
\end{tabular}

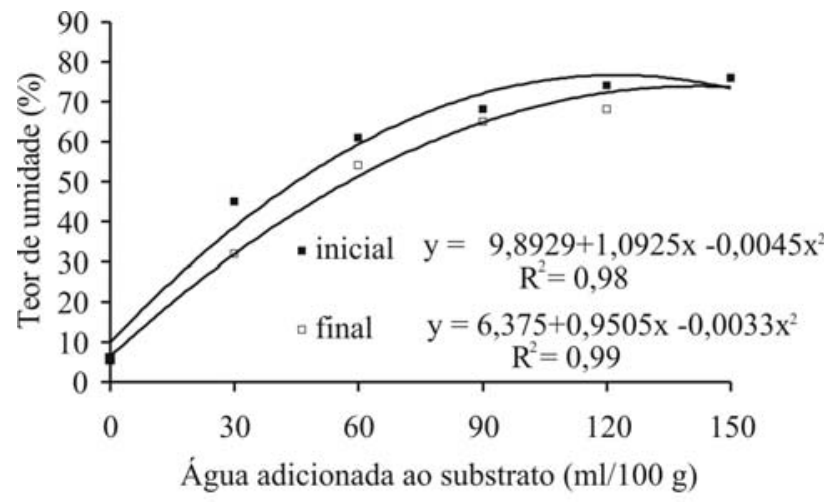

FIGURA 1 - Teores de umidade inicial e final, após o término do teste de emergência de plântulas, do substrato vermiculita umedecido com diferentes quantidades de água.

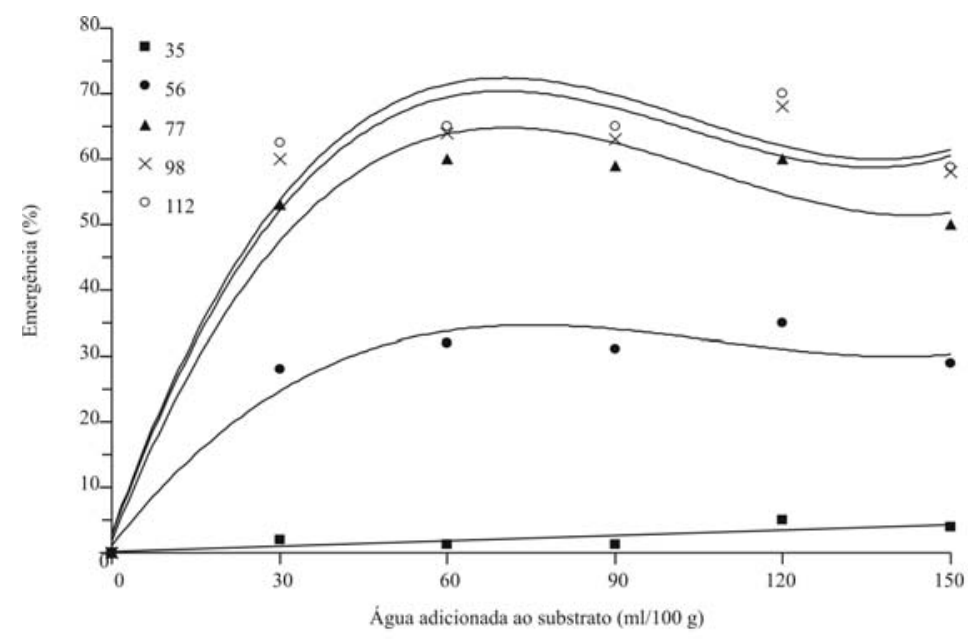

FIGURA 2 - Emergência das plântulas de pupunheira em substrato vermiculita umedecido com diferentes quantidades de água, contabilizada aos 35 dias $\left(\mathrm{y}=0,1786+0,0267 \mathrm{x}, \mathrm{R}^{2}=0,69\right) ; 56$ dias $(\mathrm{y}=$ $\left.1,1508+1,0859 \mathrm{x}-0,0111 \mathrm{x}^{2}+3 \mathrm{E}-5 \mathrm{x}^{3}, \mathrm{R}^{2}=0,95\right) ; 77 \operatorname{dias}\left(\mathrm{y}=1,8413+2,1329 \mathrm{x}-0,0225 \mathrm{x}^{2}+7 \mathrm{E}-\right.$ $\left.5 \mathrm{x}^{3}, \mathrm{R}^{2}=0,97\right) ; 98 \operatorname{dias}\left(\mathrm{y}=2,4286+2,3817 \mathrm{x}-0,0263 \mathrm{x}^{2}+9 \mathrm{E}-5 \mathrm{x}^{3}, \mathrm{R}^{2}=0,95\right)$ e $112 \operatorname{dias}(\mathrm{y}=2,8968$ $\left.+2,389 \mathrm{x}-0,0257 \mathrm{x}^{2}+8 \mathrm{E}-5 \mathrm{x}^{3}, \mathrm{R}^{2}=0,94\right)$ após a semeadura. 


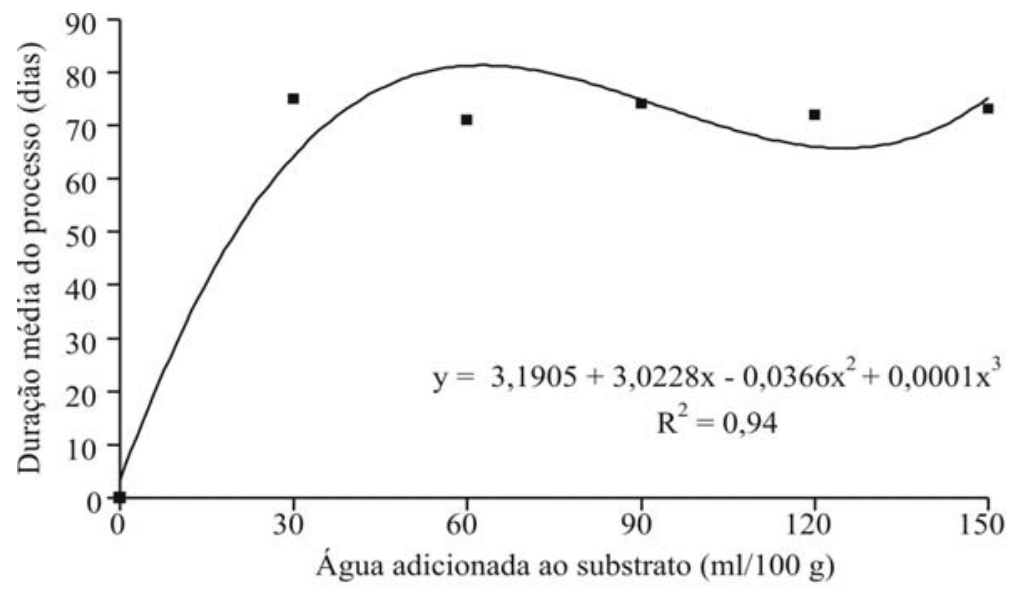

FIGURA 3 - Duração média do processo germinativo de sementes de pupunheira em substrato vermiculita umedecido com diferentes quantidades de água.

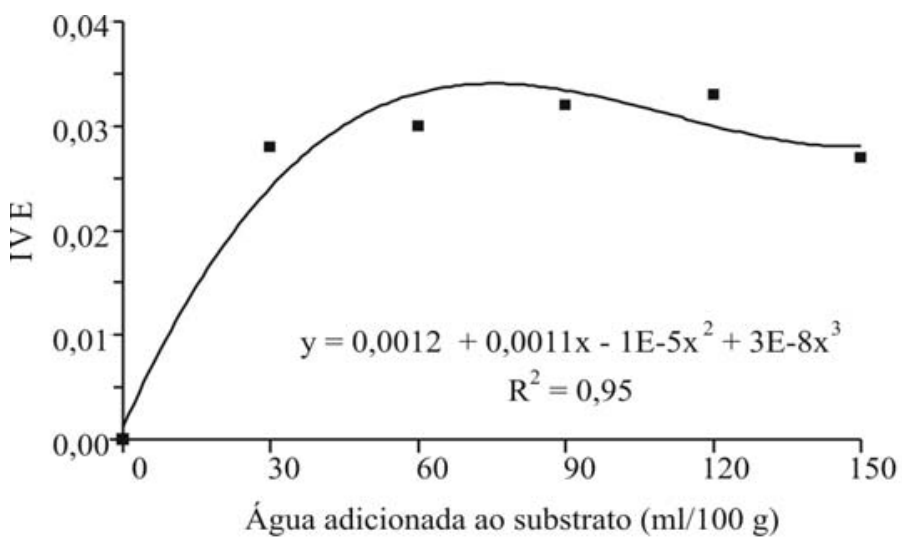

FIGURA 4 - Índice de Velocidade de Emergência (IVE) de plântulas de pupunheira em substrato vermiculita umedecido com diferentes quantidades de água.

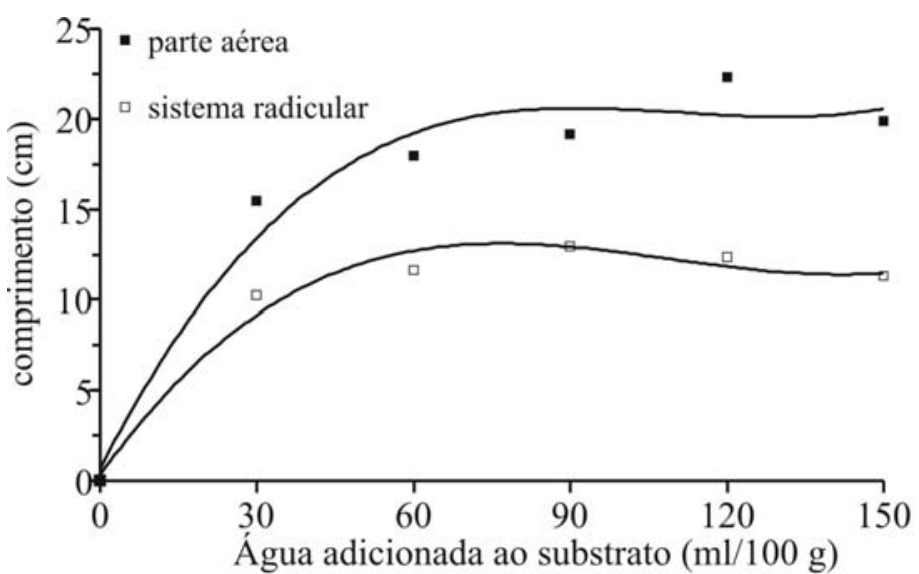

FIGURA 5 - Comprimento da parte aérea $\left(y=0,6806+0,5701 x-0,0053 x^{2}+2 E-5 x^{3}, r^{2}=0,96\right)$ e do sistema radicular $\left(\mathrm{y}=0,3193+0,4063 \mathrm{x}-0,0041 \mathrm{x} 2+1 \mathrm{E}-5 \mathrm{x} 3, \mathrm{r}^{2}=0,98\right)$ de plântulas de pupunheira em substrato vermiculita umedecido com diferentes quantidades de água. 


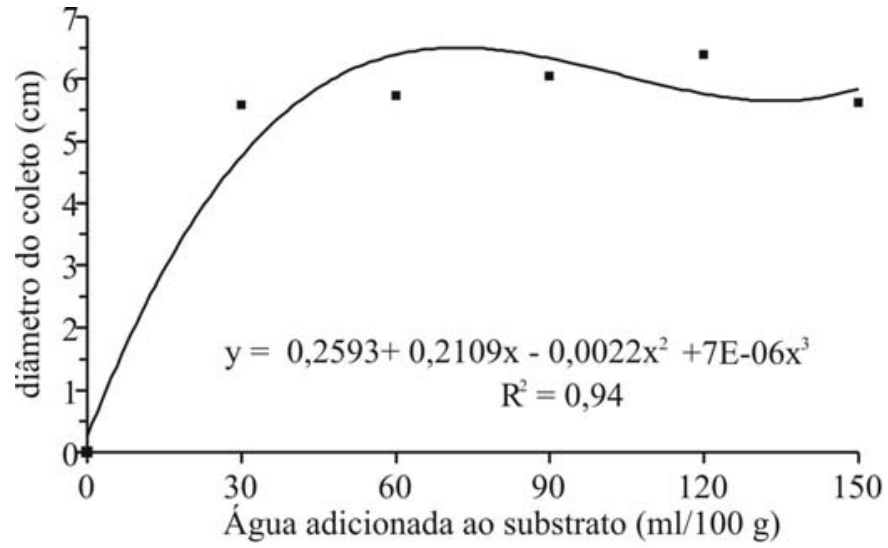

FIGURA 6 - Diâmetro do coleto de plântulas de pupunheira em substrato vermiculita umedecido com diferentes quantidades de água.

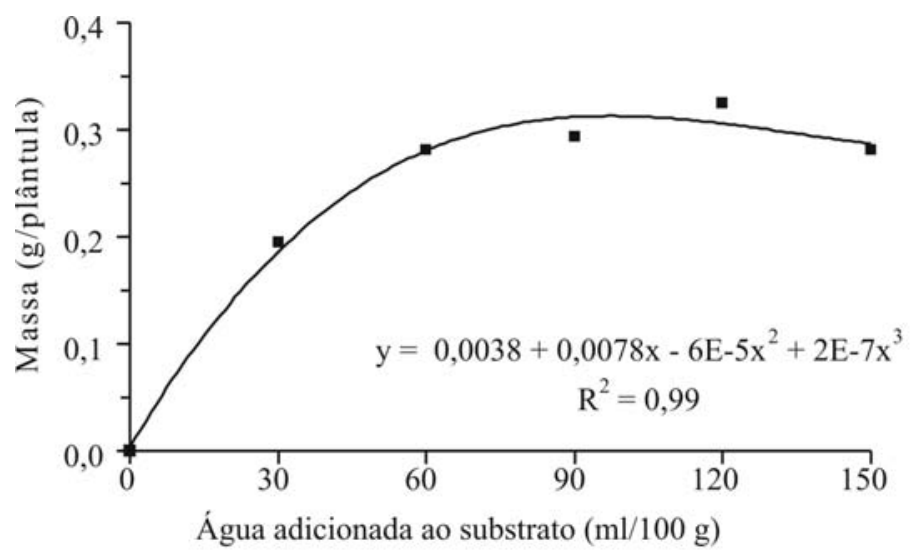

FIGURA 7 - Massa seca de plântulas de pupunheira em substrato vermiculita umedecido com diferentes quantidades de água.

\section{CONCLUSÃO}

O umedecimento da vermiculita com água, nas quantidades de 60 a $90 \mathrm{ml} / 100 \mathrm{~g}$ de substrato, apresentou porcentagem final de emergência das plântulas e duração média do processo germinativo similar, entretanto a utilização de $90 \mathrm{ml}$ possibilitou a maior velocidade da emergência e vigor de plântulas

\section{REFERÊNCIAS}

BRASIL. Ministério da Agricultura e Reforma Agrária. Regras para análise de sementes. BrasíliaDF: SNDA/DNPV/CLAV, 1992.365 p.

BIANCHETTI, A.; AMARAL, E. Dia médio e velocidade de germinação de sementes de cebola (Allium cepa L.). Pesquisa Agropecuária Brasileira, Brasília, v. 13, p.33-44, 1978.
ELIAS, M.E.A.; FERREIRA, S.A.N.; OLIVEIRA, D.F. Emergência de plântulas de tucumã (Astrocaryum aculeatum) em função da posição de semeadura. Acta Amazônica, Manaus, v.36, n.3, p. 385-388, 2006.

FERREIRA, S.A.N.; SANTOS, L.A. Viabilidade de sementes de pupunheira (Bactris gasipaes Kunth.). Acta Amazônica, Manaus, v. 22, n.3, p. 303-307, 1992.

FERREIRA, S.A.N.; GENTIL, D.F.O. Extração, embebição e germinação de sementes de tucumã (Astrocaryum aculeatum). Acta Amazônica, Manaus, v.36, n.2, p. 141-146, 2006.

FONSECA, S.C.L.; FREIRE, H.B. Sementes recalcitrantes: problemas na pós-colheita. Bragantia, Campinas, v.62, n.2, p.297-303, 2003.

IOSSI, E.; SADER, R.; PIVETTA, K.F.L.; BARBOSA. J.C. Efeitos de substratos e temperaturas na germinação de sementes de tamareira-anã (Phoenix 
roebelenii O'Brien). Revista Brasileira de Sementes, Pelotas, v.25, n.2, p. 63-69, 2003.

LEDO, A.S.; MEDEIROS-FILHO, S.; LEDO, F.J.S.; ARAÚJO, E.C. Efeito do tamanho de semente, do substrato e pré-tratamento em sementes de pupunha. Ciência Agronômica, Fortaleza, v.33, n. 1, p.29-32, 2002.

MAGUIRE, J.D. Speed of germination: aid in selection and evaluation for seedling emergence and vigor. Crop Science, Madison, v.2, n.2, p.176-177, 1962.

MARCOS-FILHO, J. Fisiologia de sementes de plantas cultivadas. Piracicaba: FEALQ, 2005. 495p.

NAKAGAWA, J. Testes de vigor baseados na avaliação de plântulas. In: VIEIRA, R.D.; CARVALHO, N.M. de. Testes de vigor em sementes. Jaboticabal: FUNEP, 1994. p.49-85.

NISHIKAWA, M. A. N.; MORO, J. R.; BANDEL, G. Cultura da pupunha para produção de palmito. Piracicaba: Divisão de Biblioteca e Documentação/ ESALQ, 1998. v.11, 31 p. Série Produtor Rural.
PHANEENDRANATH, B.R. Influence of amount of water in paper towel on stand germination tests. Journal of Seed Technology, Borse, v.5, n.2, p.82-87, 1980.

RAMOS, M.B.P.; VARELA, V.P.; MELO, M.F.F. Influência da temperatura e da quantidade de água no substrato sobre a germinação de sementes de Ochroma pyramidale (Cav. ex Lam.) Urban (pau-debalsa). Acta Amazônica, Manaus, v.36, n.1, p. 103106, 2006

TAO, K.L.J. Physiological rupture of hypocotylis in germination and vigor tests. Journal of Seed Technology, Borse, v.6, n.3, p.1-8, 1981.

TOLEDO, F.F.; PEDREIRA, A.A.S. Quantidade de solução de nitrato de potássio e germinação de sementes de capim-colonião. Revista Brasileira de Sementes, Pelotas, v.6, n.1, p.61-70, 1984.

VARELA, V.P.; RAMOS, M.B.P.; MELO, M.F.F. Umedecimento do substrato e temperatura na germinação de sementes de angelim-pedra (Dinizia excelsa Ducke). Revista Brasileira de Sementes, Pelotas, v.27, n.2, p.130-135, 2005. 